\title{
A new three-step hybrid approach is a safe procedure for incisional hernia: early experiences with a single centre retrospective cohort
}

\author{
L. Matthijs van den Dop ${ }^{1}$ (D) Gijs H. J. de Smet ${ }^{1}$ (D) Michaël P. A. Bus ${ }^{3} \cdot$ Johan F. Lange $^{1,2} \cdot$ Sascha M. P. Koch ${ }^{3}$. \\ Willem E. Hueting ${ }^{3}$
}

Received: 4 June 2020 / Accepted: 2 September 2020 / Published online: 12 September 2020

(c) The Author(s) 2020

\begin{abstract}
Purpose In this study, a three-step novel surgical technique was developed for incisional hernia, in which a laparoscopic procedure with a mini-laparotomy is combined: so-called 'three-step incisional hybrid repair'. The aim of this study was to reduce the risk of intestinal lacerations during adhesiolysis and recurrence rate by better symmetrical overlap placement of the mesh.

Objectives To evaluate first perioperative outcomes with this technique.

Methods From 2016 to 2020, 70 patients (65.7\% females) with an incisional hernia of $>2$ and $\leq 10 \mathrm{~cm}$ underwent a elective three-step incisional hybrid repair in two non-academic hospitals performed by two surgeons specialised in abdominal wall surgery. Intra- and postoperative complications, operation time, hospitalisation time and hernia recurrence were assessed.

Results Mean operation time was $100 \mathrm{~min}$. Mean hernia size was $4.8 \mathrm{~cm}$; 45 patients $(64.3 \%)$ had a hernia of $1-5 \mathrm{~cm}, 25$ patients (35.7\%) of 6-10 cm. Eight patients had a grade 1 complication (11.4\%), five patients a grade 2 (7.1\%), two patients (2.8\%) a grade 4 complication and one patient (1.4\%) a grade 5 complication. Five patients had an intraoperative complication (7.0\%), two enterotomies, one serosa injury, one omentum bleeding and one laceration of an epigastric vessel. Mean length of stay was 3.3 days. Four patients (5.6\%) developed a hernia recurrence during a mean follow-up of 19.5 weeks.

Conclusion A three-step hybrid incisional hernia repair is a safe alternative for incisional hernia repair. Intraoperative complications rate was low.
\end{abstract}

Keywords Incisional hernia $\cdot$ Hybrid $\cdot$ Laparoscopic $\cdot$ Surgical technique $\cdot$ Hernia recurrence $\cdot$ Enterotomy

\section{Introduction}

Incisional hernias occur in approximately ten to fifteen percent of the general patient population after abdominal surgery [1]. This percentage may exceed over $30 \%$ in high risk patients with obesity or an abdominal aorta aneurysm (AAA) [2]. An incisional hernia can develop after any sort

L. Matthijs van den Dop

Matthijs.vandendop@gmail.com;

l.vandendop@erasmusmc.nl

1 Department of Surgery, Erasmus University Medical Centre, Room Ee-173, Dr. Molewaterplein 40, 3000 CA, PO BOX 2040, 3015 GD Rotterdam, The Netherlands

2 Department of Surgery, IJsselland Ziekenhuis, Capelle Aan Den IJssel, The Netherlands

3 Department of Surgery, Alrijne Ziekenhuis, Leiderdop, The Netherlands of abdominal wall incision. However, abdominal incision through the midline is most prone to incisional hernia development [3, 4].

Known risk factors that contribute to the development of an incisional hernia are high age, high Body Mass Index (BMI), presence of AAA, immunosuppressants, lung disease and heavy physical work. In addition to these risk factors, there are also a number of technical factors that increase the risk of developing an incisional hernia, such as wound infections, abdominal wound dehiscence and suboptimal closing of the fascia [5-7].

The laparoscopic approach is widely used since it was first introduced by LeBlanc et al. [8] in 1993 and consists of the placement of the mesh in an intraperitoneal onlay (IPOM) manner. The mesh is fixated to the abdominal wall with the use of tackers or/and sutures [9]. Laparoscopic approach seems to have an advantage over an open approach with respect to surgical site infections, shorter hospital stay 
and less postoperative pain, although it is also associated with more peroperative intestinal lesions, postoperative seroma formation and bulging as compared to the open procedure [10-12]. Bulging and recurrent hernia are especially more present in case the defect has not been closed and in case of insufficient mesh overlap [13]. Seroma infection can lead to infection, mesh removal and hernia recurrence [9, 14-16]. Furthermore, the laparoscopic approach is associated with the risk of enterotomies, serosa bowel injuries and other intraoperative complications, such as bladder injuries, especially for individuals with complex abdominal adhesions [17]. Bowel injury is a relatively uncommon complication, but raises mortality [18].

Recently, there has been some evidence for the benefit for a hybrid incisional hernia repair (a laparoscopic combined with open approach) in terms of enterotomies via safe adhesiolysis at one month follow-up [5]. However, at 1-year follow-up [19], there was no significant difference in respect to recurrence as compared to the pure laparoscopic approach. In both studies of Ahonen-Siirtola et al. [5, 19] they used a two-step hybrid approach starting with a mini-laparotomy.

In the newly developed three-step incisional hybrid repair (TIHR) in two locations of a non-academic teaching hospital in the Netherlands, a three-step procedure was used to tackle the disadvantages of the purely laparoscopic approach (i.e., seroma formation, possible bowel injury and bulging and recurrence) and giving way for more options to form an optimal surgical plan. In this study, the first experiences were assessed with this new TIHR with respect to perioperative outcomes, complications and hernia recurrences.

\section{Methods}

This retrospective observational study was conducted according to the STROBE (Strengthening the Reporting of Observational studies in Epidemiology), STROCSS (Strengthening the Reporting of Cohort Studies in Surgery) statements and the EuraHS Working Group (European Registry of Abdominal Wall Hernias) recommendations [20-22].

\section{Study design}

After obtaining approval of the local ethics committee, all patients who underwent elective TIHR in our non-academic teaching hospital between 2016 and 2020, were retrospectively assessed for perioperative outcomes and were included in the study.

Patients were first seen at the outpatient clinic by two dedicated abdominal wall surgeons who performed the intake and physical examination. An incisional hernia was defined as: 'a ventral hernia that developed after surgical trauma to the abdominal wall, including recurrences after repair of primary ventral hernias' as described by Muysoms et al. [20]. A computed tomography (CT) scan was performed when additional information about the hernia configuration was needed.

Patients were considered eligible for TIHR if the incisional hernia was $\geq 2 \mathrm{~cm} \leq 10 \mathrm{~cm}$, and were not pregnant.

\section{Data collection}

The electronic medical records of each patient were retrospectively reviewed to asses baseline patient characteristics (sex, age, smoking, chronic lung ideas, corticosteroid use, diabetes, BMI, ASA classification) hernia characteristics (hernia size, prior operation, multiple defects, location of hernia and radiological imaging used), surgical characteristics (operation time, length of stay (LOS), mesh-type class), intraoperative complications (bleeding or vessel laceration, enterotomy, serosa injury). Postoperative outcomes including wound infections, fever, postoperative pain, seroma and hernia recurrence were assessed during hospital stay and follow-up appointments.

\section{Surgical planning and patient positioning}

The preoperative $\mathrm{CT}$ scan helped plan the surgical procedure by providing valuable information about the hernia configuration (Fig. 1). The hernia location, size and contents were documented, as well as the abdominal wall musculature that could be used for mesh implementation.

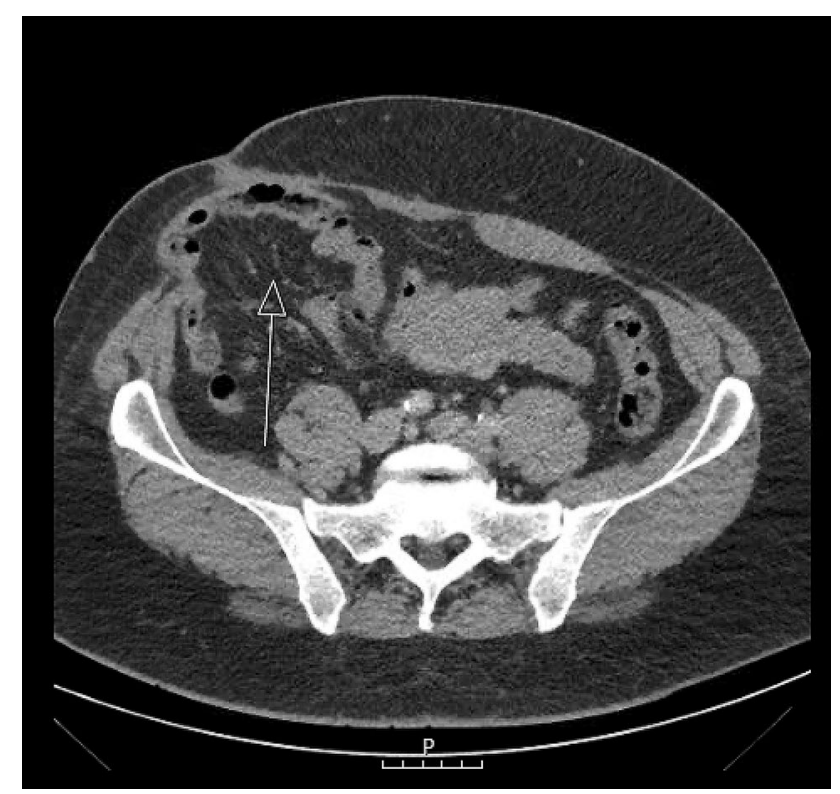

Fig. 1 Preoperative CT-scan 
Surgery was performed under general anaesthesia and antibiotic prophylaxes were administered (cefazolin $2 \mathrm{~g}$, and metronidazole $500 \mathrm{mg}$ if contamination was suspected) in all patients. The patient was positioned in supine position with one arm spread at the side where the hernia is located and the other arm alongside the body. An orogastric tube and Foley catheter were inserted on indication, the operation field was sterilised with chlorhexidine and sterile drapes were placed at all four sides of the patient.

\section{First laparoscopic part}

First, a "pneumodissection" of the hernia sac was formed with the introduction of a Veress needle in the intraabdominal space on the left subcostal region. The use of a Veress needle is a standard procedure in the Netherlands and is regarded as acceptable as using the direct trocar insertion technique [23]. This pneumodissection was formed when pressure of the $\mathrm{CO}_{2}$ intraperitoneally expands the abdomen and the hernia sac would bulge through the abdominal wall and thereby aiding in determining the length of the laparotomy incision (Fig. 2a). Concomitantly, this would facilitate a safer way for
A

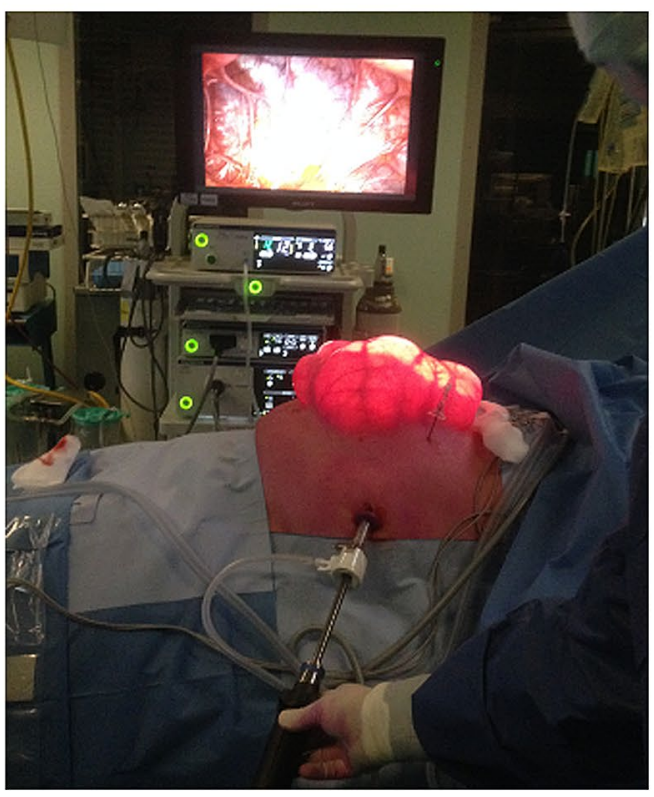

C

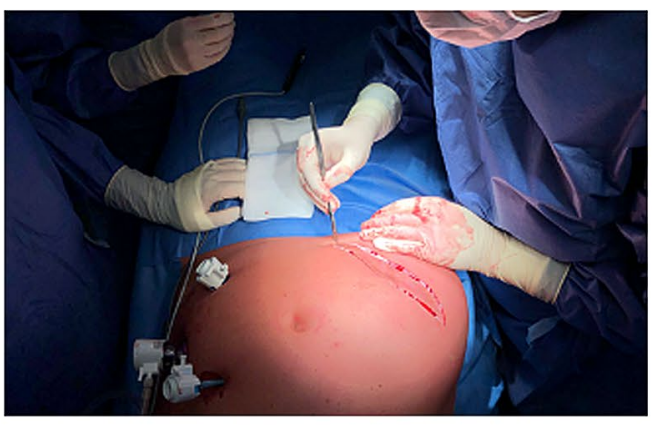

B

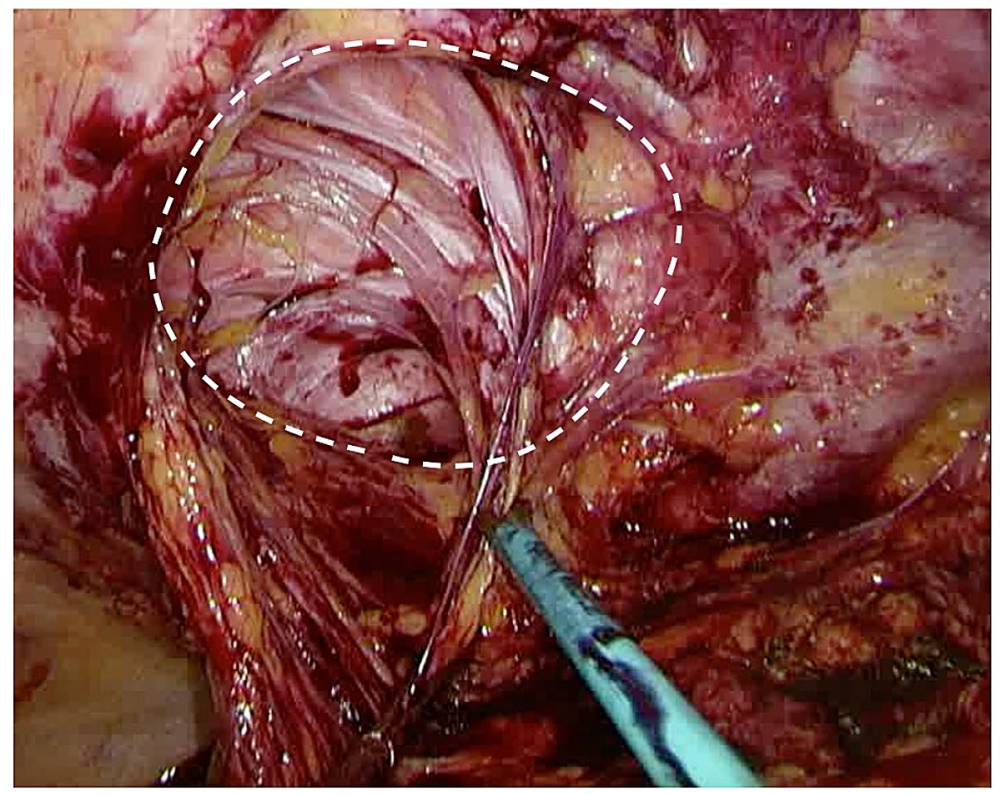

D

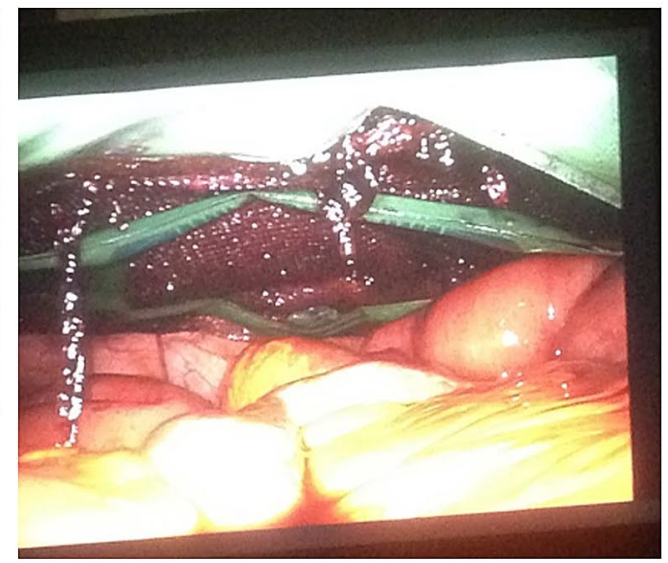

Fig. 2 a Establishing pneumoperitoneum and placing of the trocars. b Laparoscopic adhesiolysis was performed around the abdominal defect for safe continuation of the mini-laparotomy. c A mini-laparot- omy was performed over the old incision (photo was made with a different patient). d The mesh is placed in the centre of the hernia defect so that the mesh surface is spread evenly around the closed defect 
adhesiolysis, gave way for more preservation of abdominal wall, smaller laparotomy incision and optimised the surgical plan for mesh implementation. This preservation of abdominal wall could be advantageous within large hernia defects, because this will give more opportunities for defect closure if the hernia recurs.

A $12 \mathrm{~mm}$ visual port was inserted under vision on the contralateral side from the location of the abdominal wall hernia, in case of a midline hernia on de left lateral side, together with two $5 \mathrm{~mm}$ trocar ports, both on the contralateral side. The laparoscope was then introduced to inspect the abdominal cavity and identify the hernia sac. Laparoscopic start of adhesiolysis was performed for adhesions around the abdominal defect for safe continuation of the mini-laparotomy (Fig. 2b).

\section{Second open part}

Secondly, the laparoscopic procedure was interrupted, the abdomen deflated and a minimal length excision of the old scar was performed (Fig. 2c). The dissection was continued through the subcutaneous fat and access to the extraperitoneal space was obtained. The hernia sac was opened, open adhesiolysis was performed if laparoscopic adhesiolysis was deemed too dangerous because of unclear view and potential contents of the hernia sac were repositioned in the intra-abdominal space. After excision of the hernia sac, the edges of the fascia were exposed circumferentially. In case of an Echo Positioning System was used, the mesh was put in through the incision and the posterior rectus fascia was closed with PDS (polydiaxone) loop sutures.

\section{Third laparoscopic part}

Thirdly, the procedure was continued laparoscopically, the abdomen inflated and in the case of a Ventralight ST mesh, the mesh was now introduced into the abdominal cavity through the laparoscopic port. With the use of a Sorbafix tacker, the mesh was fixated to the abdominal wall. When using the Echo mesh, a disposable titanium body was fixated on the mesh. Through the expansion of the titanium body inside the abdomen, the mesh could easily be positioned in the centre of the closed hernia defect and ensure that the mesh surface was spread evenly (Fig. 2d). After the fixation in a single or double crown manner, the titanium body was evacuated. In case of use of a Ventralight ST mesh, 4 transfascial sutures with resorbable polyglactin were used for correct positioning before tackering. Lastly, a laparoscopic overview was used to ensure correct mesh position. The trocars and Veress needle were always removed under vision, closed suction drains were placed under the subcutaneous space if the woundsurface deemed considerably of size. The subcutaneous fat was approximated with Vicryl and the skin was sutured with resorbable monofilament sutures.

\section{Primary and secondary outcomes}

The primary outcome was intraoperative complications (i.e., bowel injury, serosa injury or other complications related to the operative procedure). Secondary outcomes were LOS, recurrence and postoperative complications (classified with the Clavien-Dindo classification of surgical complications [24]).

\section{Follow-up}

Patients were seen one month after surgery at the outpatient clinic by the surgeon who performed the surgery. Postoperative discomfort was discussed and physical examination was performed. If patients did not develop new complaints, they were discharged from follow-up. Patients were instructed to contact the hospital if new symptoms emerged.

\section{Statistical analysis}

Statistical analysis was performed with SPSS software version 26. Continuous variables are presented as mean and standard deviation (SD) or median. Discrete variables are presented as absolute numbers and percentages.

\section{Results}

A total of 82 patients that underwent TIHR were retrospectively analysed. Four patients were excluded because they had a two-step hybrid procedure, two patients were excluded because the initially TIHR procedure was converted to an open procedure due to primary closing of a small defect size $(1.5 \mathrm{~cm})$ and a defect that had a width of $12 \mathrm{~cm}$, requiring a transverse incision. Two patients had a primary ventral hernia and four patients had a hernia defect that was larger than $10 \mathrm{~cm}$. All patients were operated between December 2016 and March 2020.

\section{Patient baseline characteristics}

The patient baseline characteristics are shown in Table 1 . Forty-six patients $(65.7 \%)$ were females and the mean age was 59 years with a standard deviation of 12 years. Mean follow-up duration was 19.5 weeks $( \pm 25.3)$. 
Table 1 Patient baseline characteristics for patients with TIHR

\begin{tabular}{ll}
\hline TIHR & $N=70(\%)$ \\
\hline Sex & \\
Male & $24(34.3)$ \\
Female & $46(65.7)$ \\
Age (years) & $59(12.0)$ \\
Smokers & $14(20.0)$ \\
Chronic lung disease & $14(20.0)$ \\
Corticosteroid use & $11(15.7)$ \\
Diabetes & $11(15.7)$ \\
BMI (kg/m ${ }^{3}$ ) & $30(6.1)$ \\
ASA classification & \\
1 & $5(7.1)$ \\
2 & $44(62.9)$ \\
3 & $21(30)$ \\
Follow-up (weeks) & $19.5(25.3)$ \\
\hline
\end{tabular}

Continuous variables are presented as mean and (SD). Discrete variable are presented as absolute number and (percentage)

ASA American society of anaesthesiologist, $B M I$ body mass index

Table 2 Hernia characteristics for patients with TIHR

\begin{tabular}{ll}
\hline Hernia characteristics & $N=70(\%)$ \\
\hline Hernia size (mean width in cm) & $4.8(2.4)$ \\
$2-5 \mathrm{~cm}$ & $45(64.3)$ \\
$6-10 \mathrm{~cm}$ & $25(35.7)$ \\
Prior operations & \\
Open & $43(61.4)$ \\
Laparoscopic & $27(38.6)$ \\
Operation subtype & \\
Gastrointestinal disease & $42(60.0)$ \\
Abdominal wall hernia & $12(17.1)$ \\
Gynaecological disease & $7(10.0)$ \\
Urological disease & $6(8.5)$ \\
Vascular disease & $3(4.3)$ \\
Location of hernia & \\
Midline & $27(38.6)$ \\
Paramedian & $15(21.4)$ \\
Flank & $15(21.4)$ \\
Parastomal & $5(7.1)$ \\
Trocar & $3(4.3)$ \\
Hypogastric & $3(4.3)$ \\
Patients with multiple defects & $18(25.7)$ \\
Radiology & \\
CT scan & $44(62.8)$ \\
Ultrasound & $21(30.0)$ \\
CT and ultrasound & $3(4.3)$ \\
No radiology performed & $2(2.9)$ \\
\hline
\end{tabular}

Continuous variables are presented a mean and (SD). Discrete variable are presented as absolute number and (percentage)

\section{Hernia characteristics}

Hernia characteristics are presented in Table 2. Mean hernia size in width was $4.8( \pm 2.4)$ centimetres. The most common surgery subtype prior to the incisional hernia was gastrointestinal surgery with $60 \%$ of the incisional hernias. Other common surgical procedures prior to developing an incisional hernia were primary ventral hernia repairs. In $38.6 \%$ of all cases the hernia was located in the midline and $25.7 \%$ of patients had multiple hernia defects.

\section{Surgical characteristics}

Surgical characteristics are presented in Table 3. The mean operation time was 100.4 min with a standard deviation of $44.8 \mathrm{~min}$. LOS was 3.3 days, with a standard deviation of 3.0 days. There were five intraoperative complications (7.0\%). One laceration of an epigastric vessel, one serosa injury and two enterotomies of the small bowel that were identified immediately and were sutured with PDS. One patient had a bleeding of the omentum, but this patient was known with severe liver cirrhosis. All patients recovered without further complications. The Ventralight ST mesh was used in most cases (45.7\%), next to the Prolene mesh (18.6\%). The Echo positioning system was used in $27.2 \%$ of cases depending on the surgeon's preference. The biological Phasix mesh was used when there was doubt about contamination during the procedure $(7.1 \%)$.

\section{Postoperative outcomes}

Postoperative complications are shown in Table 4. The most common postoperative complication was postoperative pain, that needed additional analgesia (5.7\%). Postoperative pain medication was paracetamol and nonsteroidal anti-inflammatory drugs (NSAID). This additional analgesia (i.e., opioids) was given after discharge of the patient for

Table 3 Surgical characteristics for patients with TIHR

\begin{tabular}{ll}
\hline Surgical characteristics & \\
\hline Operation time (minutes) & $100(44.8)$ \\
LOS (days) & $3.3(3.0)$ \\
Mesh type class $^{\mathrm{a}}$ & $N=70(\%)$ \\
3 (Ventralight ST) & $32(72.9)$ \\
2a (Prolene) & $13(18.6)$ \\
$6 \mathrm{~b}$ (Phasix) & $5(7.1)$ \\
3 (Sepramesh ST) & $1(1.4)$ \\
\hline
\end{tabular}

Continuous variables are presented as mean and (SD). Discrete variable are presented as absolute number and (percentage)

LOS length of stay

${ }^{\text {a }}$ Classification system used as described by Klinge et al. [41] 
Table 4 Complications in patients with TIHR

\begin{tabular}{lll}
\hline Complications & $N=70(\%)$ & Clavien-Dindo \\
\hline Intraoperative complications & $5(7.0)$ & \\
Laceration of a. or v. epigastrica & $1(1.4)$ & \\
Enterotomy of small bowel & $2(2.8)$ & \\
Serosa injury & $1(1.4)$ & \\
Bleeding of omentum & $1(1.4)$ & \\
Postoperative complications & $18(25.7)$ & \\
Hospital acquired pneumonia & $2(2.8)$ & 2 \\
Hypotension & $2(2.8)$ & 2 \\
Seroma & $2(2.8)$ & 1 \\
Surgical site infection & $1(1.4)$ & 1 \\
Gastroparesis & $1(1.4)$ & 1 \\
Low haemoglobin & $1(1.4)$ & 2 \\
Respirator insufficiency & $2(2.8)$ & 4 \\
Problems with intake & $1(1.4)$ & 1 \\
Prolonged pain requiring analgesia & $4(5.6)$ & 1 \\
Haematoma & $1(1.4)$ & 1 \\
Postoperative abdominal sepsis & $1(1.4)$ & 5 \\
Hernia recurrence & $4(5.6)$ & \\
\hline
\end{tabular}

Discrete variables are presented as absolute number and (percentage), Clavien-Dindo classification is used for the classification of surgical postoperative complications

one week. There were no patients who developed chronic postoperative pain (pain lasting longer than 2 months after surgery with exclusion for other causes as defined by Macrae et al. [25]). One patient had low haemoglobin levels postoperatively, which required blood transfusion. Two patients developed hypotension, which had to be managed at the ICU for one night. Both patients recovered after administration of antiarrhythmic medication. Two patients suffered from respirator insufficiency, with one patient having an unknown giant hiatal hernia with multiple organs in the chest. Another patient had a community acquired pneumonia who had to be transfered to the ICU because of low saturation. One patient known with severe comorbidities developed abdominal sepsis after the operation and deceased after 15 days. Four patients (5.6\%) developed a hernia recurrence during a mean follow-up time of 19.5 weeks and one patient was lost during follow-up.

\section{Discussion}

Incisional hernia repair remains a challenging issue. In this study, a novel technique was used and evaluated based on the perioperative outcomes. The incidence of intraoperative complications was low (7.0\%) and most postoperative complications did not seem to have a relationship with the procedure itself. Therefore, the three-step TIHR appears to be a safe procedure.

Using the three-step TIHR procedure, adhesions around and within the abdominal wall defect and intestines can be visualised more clearly after the pneumodissection is established. Subsequently, the surgeon is able to safely perform the adhesiolysis laparoscopically before entering the abdominal space via the mini-laparotomy. In doing so, the risk of enterotomy is minimalised and the surgeon is able to give way for a patient tailored hernia procedure.

Another advantage of this three-step TIHR is the preservation of abdominal wall. Through foresight of the hernia configuration, optimal excision of the hernia sac could be achieved when desufflating the pneumoperitoneum. By this optimal excision, preservation of abdominal wall tissue could be facilitated and therefore, giving more options for further surgery if the patients develops a recurrence.

Other studies reporting on ventral hernia hybrid repair procedures appear to be promising as well [5, 19, 26-33]. However, these studies included a low number of patients and multiple types of different hernias (primary, incisional, flank or stomal). Ahonen-Siirtola et al. [5, 19] was the first who performed a randomised control trial (RCT) on hybrid incisional hernia repair and found promising results for intraoperative complications as compared to laparoscopic incisional hernia repair (LIHR) with respect to incidence of enterotomies (1.1\% vs 5.3\%).

Other hybrid procedure studies reported intraoperative complications ranging from 0 to $16.7 \%$ [5, 28-30, 33]. In the study that reported $16.7 \%$ intraoperative complications, they only treated patients with complex abdominal adhesions [23]. Despite the small sample size of these studies, a positive trend is visible in respect to hybrid procedures. The intraoperative complication rate of LIHR procedures is reported to be $9.6-13.2 \%$ [17, 28, 34]. Moreover, the enterotomies reported by Ahonen-Siirtola et al. [28] were all detected during the hybrid procedure, while 4 of the 5 bowel injuries in the laparoscopic group were undetected at the time of surgery, and one of those patients died after developing a septic shock as a consequence of the bowel injury 69 days later.

Other hypothesised advantages of the hybrid repair were a lower rate of seroma formation and bulging when closing the preperitoneal fascial defect. A study by Zeichen et al. [35] comparing closing of the preperitoneal defect with subsequent laparoscopic ventral hernia repair (IPOMPlus) versus laparoscopic ventral hernia repair with normal IPOM showed significant reduction in the incidence of seroma formation. Another study of Clapp et al. [36] found a significant reduction in bulging after using IPOM-Plus in LVHR. However, in a RCT by Lambrechts et al. [37] these two aspects were similar in both groups (IPOM-Plus vs. standard IPOM). In the meta-analysis of Awaiz et al. [10] 
on the subject of elective LIHR versus open repair, seroma incidence in LIHR has been reported to be $4.4-35.5 \%$. In the RCT of Ahonen-Siirtola et al. [5] the clinically observed seroma formation was $48.9 \%$ in the laparoscopic group and $31.4 \%$ in the hybrid group. In this study, a fairly low seroma incidence was reported (2.8\%). This could be due to the fact that patients were only seen one time postoperatively at the outpatient clinic without radiological check-up and only returned when they reported complaints, underestimating the seroma incidence.

Postoperative bulging is recognised as an adverse outcome in LVHR and can be perceived as cosmetically dissatisfying. The anatomic aetiology of bulging is that neither the hernia defect nor the rectus diastasis was closed during the hernia repair [38]. It is to the belief of the IEHS (International EndoHernia Society) that 'a failure to position/fix the mesh flat may contribute to postoperative bulging' and they recommend that 'the mesh should be tensioned appropriately such that the mesh is flat without any wrinkles/folds following desufflation of the abdomen'. In this study, by ensuring an even underlay with the third-step as laparoscopic overview, a flat mesh fixation is attempted, also reducing the risk of enterocutaneous fistula formation by wrinkling of the mesh.

Postoperative complications occurred in $25.7 \%$ of the patients in this study. This complication rate is comparable with studies involving laparoscopic incisional hernia repair [34, 39-41]. A reason for this complication rate could be that the $32 \%$ of patients had an ASA classification of 3 . These patients were more prone to develop postoperative complications due to their comorbidities.

Recurrences in hybrid incisional hernia repairs are somewhat underreported due to the novelty of the procedure and studies. In the RCT by Ahonen-Siirtola et al. [19], at 1-year follow-up, no statistically significant difference in hernia recurrence rates between both procedures was found (LIHR 7\% vs hybrid incisional hernia repair 6\%). Other hybrid incisional hernia repairs studies have a very low number of patients included in the studies, which makes it hard to draw conclusion about recurrence rates [27, 29, 30]. Recurrence rates found in LIHR are reported to be $9.7 \%$ (12 months) - $24.0 \%$ (35 months) [17, 40]. The recurrence rate in this study was $5.6 \%$ with a mean follow-up time of 19.5 weeks. Owing to the short follow-up period, no hard conclusion could be drawn from this recurrence rate.

Two dedicated abdominal wall surgeons performed the procedure. WH was the first surgeon to incorporate this procedure in patients with incisional hernias. To perform hybrid procedures for SK as well, an one-time participation in a hybrid procedure with WH was needed to attain the skills needed for implementing this procedure in the daily practice of SK. Therefore, it could be stated that this procedure is well feasible to transfer amongst abdominal wall surgeons with laparoscopic expertise, without raising costs or extending a large amount of operation time.

\section{Limitations}

This study has some limitations. First, the outcomes of this study are not based on a randomised data and all data were retrospectively collected and analysed, which gives a potential risk of selection bias. Furthermore, the follow-up appointments were only made one month pos. After this appointment, patients were instructed to return to the outpatient clinic if new complaints occurred. This shortened the follow-up duration and may have underestimated long-term postoperative complications, such as hernia recurrences, as well as seromas. On the other hand, patients were clearly instructed with signs and symptoms and when to reach out to the outpatient clinic.

\section{Conclusion}

The hybrid approach in case of incisional hernia with a three-step procedure as used in this study is a feasible, safe and easy to incorporate surgical approach. The intraoperative complication rate was low and postoperative complications did not seem to be related to the surgical procedure. Prospective research with standardised radiological followup is needed to further affirm the postulated benefits in this study [42].

\section{Author contributions Not applicable.}

Funding No financial support was received in support of this manuscript.

Data availability All data and material are stored on a computer in the local hospital.

Code availability SPSS version 26.0 has been used to do all calculations in this article.

\section{Compliance with ethical standards}

Conflict of interest There are no conflicts of interest to declare.

Ethics approval This study is approved by the ethics committee of the local hospital.

Consent to participate Permission was given for data retrieval from medical charts by the ethics committee, and signed informed consent forms were received from patients.

Consent for publication The local ethics committee and patients gave consent for the publication of this article. 
Open Access This article is licensed under a Creative Commons Attribution 4.0 International License, which permits use, sharing, adaptation, distribution and reproduction in any medium or format, as long as you give appropriate credit to the original author(s) and the source, provide a link to the Creative Commons licence, and indicate if changes were made. The images or other third party material in this article are included in the article's Creative Commons licence, unless indicated otherwise in a credit line to the material. If material is not included in the article's Creative Commons licence and your intended use is not permitted by statutory regulation or exceeds the permitted use, you will need to obtain permission directly from the copyright holder. To view a copy of this licence, visit http://creativecommons.org/licenses/by/4.0/.

\section{References}

1. Nachiappan S, Markar S, Karthikesalingam A, Ziprin P, Faiz O (2013) Prophylactic mesh placement in high-risk patients undergoing elective laparotomy: a systematic review. World J Surg 37(8):1861-1871

2. Jairam AP, Timmermans L, Eker HH, Pierik R, van Klaveren D, Steyerberg EW et al (2017) Prevention of incisional hernia with prophylactic onlay and sublay mesh reinforcement versus primary suture only in midline laparotomies (PRIMA): 2-year follow-up of a multicentre, double-blind, randomised controlled trial. Lancet 390(10094):567-576

3. Mudge M, Hughes LE (1985) Incisional hernia: a 10 year prospective study of incidence and attitudes. Br J Surg 72(1):70-71

4. Kingsnorth A, LeBlanc K (2003) Hernias: inguinal and incisional. Lancet 362(9395):1561-1571

5. Ahonen-Siirtola M, Nevala T, Vironen J, Kossi J, Pinta T, Niemelainen $\mathrm{S}$ et al (2018) Laparoscopic versus hybrid approach for treatment of incisional ventral hernia: a prospective randomized multicenter study of 1-month follow-up results. Hernia 22(6):1015-1022

6. van Ramshorst GH, Nieuwenhuizen J, Hop WC, Arends P, Boom J, Jeekel J et al (2010) Abdominal wound dehiscence in adults: development and validation of a risk model. World $\mathbf{J}$ Surg 34(1):20-27

7. Bucknall TE, Cox PJ, Ellis H (1982) Burst abdomen and incisional hernia: a prospective study of 1129 major laparotomies. Br Med J (Clin Res Ed) 284(6320):931-933

8. LeBlanc KA, Booth WV (1993) Laparoscopic repair of incisional abdominal hernias using expanded polytetrafluoroethylene: preliminary findings. Surg Laparosc Endosc 3(1):39-41

9. Bittner R, Bingener-Casey J, Dietz U, Fabian M, Ferzli GS, Fortelny RH et al (2014) Guidelines for laparoscopic treatment of ventral and incisional abdominal wall hernias (international endohernia society (IEHS)-part 1. Surg Endosc 28(1):2-29

10. Awaiz A, Rahman F, Hossain MB, Yunus RM, Khan S, Memon B et al (2015) Meta-analysis and systematic review of laparoscopic versus open mesh repair for elective incisional hernia. Hernia 19(3):449-463

11. Forbes SS, Eskicioglu C, McLeod RS, Okrainec A (2009) Metaanalysis of randomized controlled trials comparing open and laparoscopic ventral and incisional hernia repair with mesh. $\mathrm{Br}$ J Surg 96(8):851-858

12. Soliani G, De Troia A, Portinari M, Targa S, Carcoforo P, Vasquez $G$ et al (2017) Laparoscopic versus open incisional hernia repair: a retrospective cohort study with costs analysis on 269 patients. Hernia 21(4):609-618

13. Guerin G, Turquier F (2013) Impact of the defect size, the mesh overlap and the fixation depth on ventral hernia repairs: a combined experimental and numerical approach. Hernia 17(5):647-655
14. Sauerland S, Walgenbach M, Habermalz B, Seiler CM, Miserez M (2011) Laparoscopic versus open surgical techniques for ventral or incisional hernia repair. Cochrane Database Syst Rev 3:CD007781

15. Edwards C, Angstadt J, Whipple O, Grau R (2005) Laparoscopic ventral hernia repair: postoperative antibiotics decrease incidence of seroma-related cellulitis. Am Surg 71(11):931-935 (discussion 5-6)

16. Sodergren MH, Swift I (2010) Seroma formation and method of mesh fixation in laparoscopic ventral hernia repair-highlights of a case series. Scand J Surg 99(1):24-27

17. Eker HH, Hansson BM, Buunen M, Janssen IM, Pierik RE, Hop WC et al (2013) Laparoscopic vs. open incisional hernia repair: a randomized clinical trial. JAMA Surg 148(3):259-263

18. LeBlanc KA, Elieson MJ, Corder JM 3rd (2007) Enterotomy and mortality rates of laparoscopic incisional and ventral hernia repair: a review of the literature. JSLS 11(4):408-414

19. Ahonen-Siirtola M, Nevala T, Vironen J, Kossi J, Pinta T, Niemelainen $S$ et al (2020) Laparoscopic versus hybrid approach for treatment of incisional ventral hernia: a prospective randomised multicentre study, 1-year results. Surg Endosc 34(1):88-95

20. Muysoms FE, Deerenberg EB, Peeters E, Agresta F, Berrevoet F, Campanelli G et al (2013) Recommendations for reporting outcome results in abdominal wall repair: results of a consensus meeting in palermo, Italy, 28-30 June 2012. Hernia 17(4):423-433

21. Agha RA, Borrelli MR, Vella-Baldacchino M, Thavayogan R, Orgill DP, Group S (2017) The STROCSS statement: strengthening the reporting of cohort studies in surgery. Int J Surg 46(198):202

22. von Elm E, Altman DG, Egger M, Pocock SJ, Gotzsche PC, Vandenbroucke JP et al (2014) The strengthening the reporting of observational studies in epidemiology (STROBE) statement: guidelines for reporting observational studies. Int J Surg 12(12):1495-1499

23. Agresta F, De Simone P, Ciardo LF, Bedin N (2004) Direct trocar insertion vs Veress needle in nonobese patients undergoing laparoscopic procedures: a randomized prospective singlecenter study. Surg Endosc 18(12):1778-1781

24. Clavien PA, Barkun J, de Oliveira ML, Vauthey JN, Dindo D, Schulick RD et al (2009) The clavien-dindo classification of surgical complications: five-year experience. Ann Surg 250(2):187-196

25. Macrae WA (2001) Chronic pain after surgery. Br J Anaesth 87(1):88-98

26. Stoikes N, Quasebarth M, Brunt LM (2013) Hybrid ventral hernia repair: technique and results. Hernia 17(5):627-632

27. Gokmen O, Umit MF, Cenk E, Yasar O, Huseyin B, Bulent C, et al. (2016) A novel reconstruction method for giant incisional hernia: hybrid laparoscopic technic. J Minim Access Surg. https ://pubmed.ncbi.nlm.nih.gov/27251799/

28. Ahonen-Siirtola M, Rautio T, Biancari F, Ohtonen P, Makela J (2017) Laparoscopic versus hybrid approach for treatment of incisional ventral hernia. Dig Surg 34(6):502-506

29. Ji Y, Zhan X, Wang Y, Zhu J (2013) Combined laparoscopic and open technique for the repair of large complicated incisional hernias. Surg Endosc 27(5):1778-1783

30. Amaral PHF, Tastaldi L, Barros PHF, Abreu Neto IP, Hernani BL, Brasil $\mathrm{H}$ et al (2019) Combined open and laparoscopic approach for repair of flank hernias: technique description and medium-term outcomes of a single surgeon. Hernia 23(1):157-165

31. Christoudias G, Nunziata M (2016) A simplified laparoscopic approach to ventral hernia repair: a new "finned" mesh configuration with defect closure. Surg Endosc 30(6):2632-2640 
32. Romanowska M, Okninski T, Pawlak J (2016) Hybrid technique for postoperative ventral hernias: own experience. Wideochir Inne Tech Maloinwazyjne 10(4):534-540

33. Kohler G, Fischer I, Wundsam H (2018) A novel technique for parastomal hernia repair combining a laparoscopic and ostomy-opening approach. J Laparoendosc Adv Surg Tech A 28(2):209-214

34. Itani KM, Hur K, Kim LT, Anthony T, Berger DH, Reda D et al (2010) Comparison of laparoscopic and open repair with mesh for the treatment of ventral incisional hernia: a randomized trial. Arch Surg 145(4):322-328 (discussion 8)

35. Zeichen MS, Lujan HJ, Mata WN, Maciel VH, Lee D, Jorge I et al (2013) Closure versus non-closure of hernia defect during laparoscopic ventral hernia repair with mesh. Hernia 17(5):589-596

36. Clapp ML, Hicks SC, Awad SS, Liang MK (2013) Trans-cutaneous closure of central defects (TCCD) in laparoscopic ventral hernia repairs (LVHR). World J Surg 37(1):42-51

37. Lambrecht JR, Vaktskjold A, Trondsen E, Oyen OM, Reiertsen O (2015) Laparoscopic ventral hernia repair: outcomes in primary versus incisional hernias: no effect of defect closure. Hernia 19(3):479-486

38. Bittner R, Bain K, Bansal VK, Berrevoet F, Bingener-Casey J, Chen D et al (2019) Update of Guidelines for laparoscopic treatment of ventral and incisional abdominal wall hernias (international endohernia society (IEHS))-part A. Surg Endosc 33(10):3069-3139

39. Olmi S, Erba L, Magnone S, Bertolini A, Croce E (2006) Prospective clinical study of laparoscopic treatment of incisional and ventral hernia using a composite mesh: indications, complications and results. Hernia 10(3):243-247

40. Asencio F, Aguilo J, Peiro S, Carbo J, Ferri R, Caro F et al (2009) Open randomized clinical trial of laparoscopic versus open incisional hernia repair. Surg Endosc 23(7):1441-1448

41. Navarra G, Musolino C, De Marco ML, Bartolotta M, Barbera A, Centorrino T (2007) Retromuscular sutured incisional hernia repair: a randomized controlled trial to compare open and laparoscopic approach. Surg Laparosc Endosc Percutan Tech 17(2):86-90

42. Klinge U, Klosterhalfen B (2012) Modified classification of surgical meshes for hernia repair based on the analyses of 1,000 explanted meshes. Hernia 16(3):251-258

Publisher's Note Springer Nature remains neutral with regard to jurisdictional claims in published maps and institutional affiliations. 